\title{
Presynaptic Localization of Kv1.4-Containing A-Type Potassium Channels Near Excitatory Synapses in the Hippocampus
}

\author{
Edward C. Cooper, ${ }^{1}$ Antonia Milroy, ${ }^{2}$ Yuh Nung Jan, ${ }^{3}$ Lily Yeh Jan, ${ }^{3}$ and Daniel H. Lowenstein ${ }^{1,2}$ \\ Departments of ${ }^{1}$ Neurology, ${ }^{2}$ Anatomy, and ${ }^{3}$ Physiology and Biochemistry and Howard Hughes Medical Institute, \\ University of California San Francisco, San Francisco, California 94143
}

\begin{abstract}
Mammalian Shaker voltage-gated potassium channels that contain the Kv1.4 subunit exhibit rapid activation and prominent inactivation processes, which enable these channels to integrate brief (approximiately milliseconds) depolarizations over time intervals of up to tens of seconds. In the hippocampus, Kv1.4 immunoreactivity is detected at greatest density in two regions: (1) the middle molecular layer (MML), where perforant path axons synapse with dentate granule cells, and (2) the stratum lucidum (SL) of CA3, where the mossy fibers travel in tight fasciculi and form en passante synapses onto CA3 pyramidal cells. We have studied the localization of Kv1.4 within these regions in detail. First, we compared the distribution of Kv1.4 and synaptophysin (a synaptic vesicle protein primarily localized near termini) under confocal immunofluorescence mi-
\end{abstract}

croscopy. In the MML, Kv1.4 and synaptophysin immunofluorescence appeared to overlap. In the SL, however, Kv1.4 and synaptophysin staining was detected in nonoverlapping, irregular patches ( $\sim-10 \mu \mathrm{m}$ in diameter). Ultrastructural studies of these two regions revealed that Kv1.4 immunoreactivity was absent from the surface membranes of cell bodies and dendrites and occurred prominently on axons, including axonal "necks" near termini. Small excitatory synaptic boutons also were labeled in the MML; by contrast, the mossy fiber synaptic expansions in the SL were not stained. These localizations may enable Kv1.4-containing channels to regulate the process of neurotransmitter release at these excitatory synapses.

Key words: voltage-gated potassium channel; mossy fiber; presynaptic facilitation; Shaker; hippocampus; granule cells
Neuronal voltage-gated potassium channels have been shown to contribute to postsynaptic potentials, propagated action potentials, action potential firing patterns, and neurotransmitter release (Rudy, 1988; Hille, 1992). Molecular studies over the last decade have provided evidence that the wide diversity of voltage-gated potassium channels in the mammalian brain results, in part, from the expression of a large number of genes for channel subunits (Chandy and Gutman, 1995; Jan and Jan, 1997). The contribution to brain function made by a particular channel type depends on its pattern of expression within different brain regions and cell types (Llinas, 1988). Furthermore, because neurons are highly polarized cells consisting of many distinct subcellular compartments, the cellular function of a channel is determined ultimately by its localization at the ultrastructural level.

The hippocampus is suitable for studies aimed at clarifying how channel localization may relate to cellular and network properties, because plasticity at hippocampal synapses is believed to play an important role in learning and memory, and because the basic network, cells, and synapses of the rodent hippocampus have been characterized extensively in previous studies (Brown

Received Sept. 29, 1997; revised Nov. 19, 1997; accepted Nov. 19, 1997

This research was supported by National Institute of Neurological Diseases and Stroke (NINDS) Grant NS01755, a Pfizer Postdoctoral Fellowship in Neuroscience, and an American Academy of Neurology/Parke-Davis Young Investigator Award to E.C.C. A.M. was supported by NINDS Grant NS23347 to H.J. Ralston. Y.N.J. and L.Y.J. were supported by National Institute of Mental Health Grant MH48200 to the Silvio Conte Neuroscience Center at the University of California San Francisco. Y.N.J. and L.Y.J. are Howard Hughes Medical Institute Investigators. D.H.L. was supported by NINDS Grants NS32062 and NS35628 and a Klingenstein Fellowship in the Neurosciences. We thank Drs. X. W. Meng, S. M. Hersch, H. J. Ralston III, P. T. Ohara, and R. A. Nicoll for helpful discussions.

Correspondence should be addressed to Dr. Daniel H. Lowenstein, Department of Neurology, Box 0435, University of California San Francisco, San Francisco, CA 94143.

Copyright (C) 1998 Society for Neuroscience $\quad 0270-6474 / 98 / 180965-10 \$ 05.00 / 0$ and Zador, 1990; Amaral and Witter, 1995; Nicoll and Malenka, 1995). Anatomic studies have revealed that Kv1.4, a Shaker family potassium channel $\alpha$ subunit, is expressed in a distinctive pattern in the hippocampal formation (Sheng et al., 1992, 1993; Rhodes et al., 1995; Veh et al., 1995). High levels of Kv1.4 mRNA are expressed by glutamatergic neurons of the medial entorhinal cortex, dentate granule cell layer, and hippocampal pyramidal cell layer (Sheng et al., 1992). Staining with anti-Kv1.4 antibodies has revealed high expression of the protein in the middle molecular layer of the dentate gyrus and the stratum lucidum of CA3, with lower levels of immunoreactivity associated with other areas of the neuropil and cell somata. This pattern of RNA and protein localization suggested that Kv1.4-containing channels in the hippocampus might be targeted specifically to axons and synaptic termini of glutamatergic neurons (Sheng et al., 1992, 1993).

It has not been possible as yet to record intracellularly from these small axons and termini, and, hence, their electrophysiologic properties remain relatively uncharacterized. In heterologous expression studies, Kv1.4 differs from other members of the Shaker subfamily by virtue of its rapid N-type inactivation (Stuhmer et al., 1989). Kv1.4 also has uniquely prominent desensitization (or "C-type inactivation"), which develops rapidly, requires tens of seconds to recover completely, and is sensitive to extracellular potassium ion concentration (Ruppersberg et al., 1991; Pardo et al., 1992; Baukrowitz and Yellen, 1995). It is therefore of interest to determine whether Kv1.4 is expressed on axons, where it could contribute to the encoding and shaping of propagated action potentials, and whether Kv1.4 is expressed at or near synaptic termini, where it could influence the amount of transmitter release by integrating temporally dispersed incident spike activity over a milliseconds-to-seconds time range. For these reasons, we used immunohistochemistry, confocal micros- 
copy, and immunoelectron microscopy to examine the cellular and subcellular localization of Kv1.4 in the hippocampus and dentate gyrus.

\section{MATERIALS AND METHODS}

Preparation of tissue. Twelve male Sprague Dawley rats (225-275 gm) were used for these studies. Protocols for animal care were approved by the Committee for Animal Research of the University of California, San Francisco, and were in accord with United States Department of Agriculture and National Institutes of Health guidelines for humane treatment of animals. Rats were deeply anesthetized with sodium pentobarbital $(50 \mathrm{mg} / \mathrm{kg})$ and perfused via the ascending aorta with heparinized saline followed by fixative. Fixative solutions generally consisted of $4 \%$ freshly prepared paraformaldehyde/ $0.1 \%$ glutaraldehyde (PG) in phosphate buffer. Some animals used for electron microscopy were perfused with solutions of $4 \%$ paraformaldehyde, $0.5 \%$ glutaraldehyde, and $0.2 \%$ picric acid (PGP). After rapid dissection and post-fixation for $1-2 \mathrm{hr}$ at $4^{\circ} \mathrm{C}$, tissue was sectioned by vibratome at $50 \mu \mathrm{m}$ in PBS. Tissue was either stored in PBS or processed immediately for immunocytochemistry.

Antibodies and controls. The rabbit anti-Kv1.4 antibody used in this study has been characterized extensively (Sheng et al., 1992, 1993). The antibody is directed against a 21 amino acid synthetic peptide corresponding to residues $13-33$, near the cytoplasmic $N$ terminus of the protein. Antibodies were affinity-purified against the immobilized immunogenic peptide as described (Sheng et al., 1992). Western blots of rat brain membranes with the anti-Kv1.4 antibody detected a single band of $\sim 95 \mathrm{kDa}$ that comigrated with the band detected in blots of HEK-293 cells that had been transfected with Kv1.4 in mammalian expression vectors (data not shown). The pattern of hippocampal immunostaining observed here, like the ability of the antibody to recognize the Kv1.4 band on blots, was abolished by preincubation of the antibody with the immunogenic peptide. The mouse anti-synaptophysin antibody was obtained from Sigma (St. Louis, MO).

Light and laser-scanning confocal microscopy. Immunoreactions were conducted at room temperature with constant rotary shaking. Sections

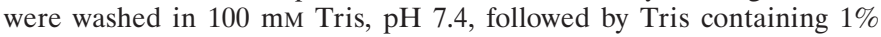
hydrogen peroxide for $30 \mathrm{~min}$. After washing in Tris, sections were blocked and permeabilized for $1 \mathrm{hr}$ in Tris-buffered saline (TBS) containing $0.1 \%$ Triton X-100, 3\% normal serum (goat or horse, depending on secondary antibodies), $0.1 \%$ bovine serum albumin, and $0.02 \%$ sodium azide. Section were incubated with primary antibodies (anti-Kv1.4 at 1:1000 dilution, anti-synaptophysin at 1:10,000) for 18-48 hr. After washing (six changes, $60 \mathrm{~min}$ total) in TBS/0.1\% Triton X-100, secondary antibodies (vector goat anti-rabbit for Kv1.4 immunoperoxidase; Jackson goat anti-rabbit for Kv1.4 immunofluorescence; Jackson donkey antimouse for synaptophysin immunofluorescence, all at 1:200) were added and incubated for $2 \mathrm{hr}$. For immunoperoxidase staining, the manufacturer's instructions were followed (ABC Elite; Vector, Burlingame, CA), and development was performed with $0.01 \%$ hydrogen peroxide.

Sections were mounted onto slides and coverslipped using Permount (Sigma) or, for immunofluorescence, ProLong (Molecular Probes, Eugene, OR). Slides were examined using a Zeiss Axiophot photomicroscope or a Bio-Rad (Hercules, CA) M-600 laser-scanning confocal microscope.

Immunoelectron microscopy. Vibratome sections were processed as for light microscopy, except that Triton X-100 was omitted from all solutions, and tissue was permeabilized by incubation in 50\% ethanol in TBS for 30 min before blocking. In some experiments, the immunoperoxidase stain was developed in the presence of $0.02 \% \mathrm{NiCl}$. Immunoreacted sections were washed in phosphate buffer, osmicated $(1 \%$ osmium tetraoxide in $0.1 \mathrm{M}$ phosphate buffer, $\mathrm{pH} 7.4,1 \mathrm{hr}$ ), stained with $1 \%$ aqueous uranyl acetate $(1 \mathrm{hr})$, dehydrated through ethanol and propylene oxide, and flat-embedded in Epon on plastic slides under Aclar coverslips. Silvergold $(\sim 80 \mathrm{~nm})$ thin sections were cut from selected regions of the dentate gyrus and hippocampus and collected on Butvar-coated single-slot grids. Thin sections were examined using a JEOL 100CX electron microscope without poststaining or after staining with Reynolds lead and photographed at 5600-19,000× magnification. Preliminary experiments compared the staining pattern associated with PG and PGP fixatives and $\mathrm{NiCl}$ enhancement. PGP perfusion resulted in improved preservation of tissue ultrastructural features but reduced penetration of immunostaining reagents. $\mathrm{NiCl}$ enhancement resulted in a peroxidase reaction product that was denser and less diffuse under electron microscopy. Optimal staining and structural preservation were obtained under the following conditions: PGP perfusion, $\mathrm{NiCl}$ enhancement, and collection of thin sections near the surface of embedded tissue blocks for examination under the electron microscope.

\section{RESULTS}

\section{Kv1.4 localization by light and confocal microscopy}

Light microscopic examination of transverse rat brain sections stained for Kv1.4 by immunoperoxidase methods revealed a distinctive pattern that appeared to respect well known layer boundaries within both the dentate gyrus and hippocampus proper (Fig. $1 A, B)$. Thus, in the dentate gyrus (Fig. $1 C$ ), intense staining was present in the middle third of the molecular layer, where perforant path input from the medial entorhinal cortex is received. Heavy staining also was noted in the region of the polymorphic layer immediately below the granule cell layer, where the granule cell axons collect to form the mossy fiber tract and produce branches that innervate hilar interneurons. Staining was lighter in the outer molecular layer (where lateral entorhinal cortex input is received) and lighter still in the inner molecular layer and granule cell layer (where associational and commissural inputs onto granule cells are received).

In the hippocampus, staining in stratum lucidum was intense and filled most of the layer. Staining also was noted in some areas within stratum pyramidale. This CA3 staining, however, was variable in appearance and unlike the more homogeneous staining seen in the middle molecular layer. In some areas, the immunoreactivity appeared in irregularly shaped patches $(2-10 \mu \mathrm{m})$ (Fig. 1D); in other areas, the antibody appeared to stain fibers or fiber bundles (Fig. $1 E$ ). Staining was lighter in stratum oriens and stratum radiatum of both CA3 and CA1.

The distribution of Kv1.4 immunoreactivity observed in the dentate and CA3 regions by light microscopy led us to hypothesize that Kv1.4-containing channels in these regions might be expressed primarily by glutamatergic neurons and perhaps in axons and terminals. The combination of fibrillar and punctate immunostaining seen with anti-Kv1.4 sera in the stratum lucidum of CA3 is reminiscent of the appearance of intracellularly filled mossy fibers (Claiborne et al., 1986; Dailey et al., 1994), which form large (up to $10 \mu \mathrm{m}$ in diameter) mossy fiber presynaptic expansions in this layer. Similar punctate staining also is seen in material immunostained for synaptophysin, which is associated with synaptic vesicles that fill the mossy fiber expansions (Grabs et al., 1994). To clarify whether the stratum lucidum puncta seen in Kv1.4-stained material reflected staining of presynaptic mossy fiber expansions, we performed confocal microscopy on tissue sections double-labeled by reaction with a monoclonal antisynaptophysin antibody and rabbit anti-Kv1.4 antisera.

Confocal images of the CA3 region stained for synaptophysin were similar to those stained for Kv1.4 (Fig. $2 A, B$ ). Both proteins appeared to be expressed at high levels within patches in stratum lucidum and at lower levels within other strata. However, double labeling revealed little overlap in the synaptophysin and Kv1.4immunoreactive patches in stratum lucidum (Fig. $2 C$ ). Thus, it appeared that the Kv1.4-containing patches did not correspond to mossy fiber expansions.

In the dentate gyrus, confocal images of Kv1.4-stained tissue exhibited a laminar pattern of expression similar to that seen in immunoperoxidase-stained material, with highest expression within the middle molecular layer (Fig. 2E). Synaptophysin immunoreactivity was strong throughout the molecular layer but was most abundant in the outer rather than in the middle third (Fig. $2 D$ ). In contrast to the large, isolated patches of synaptophysin 

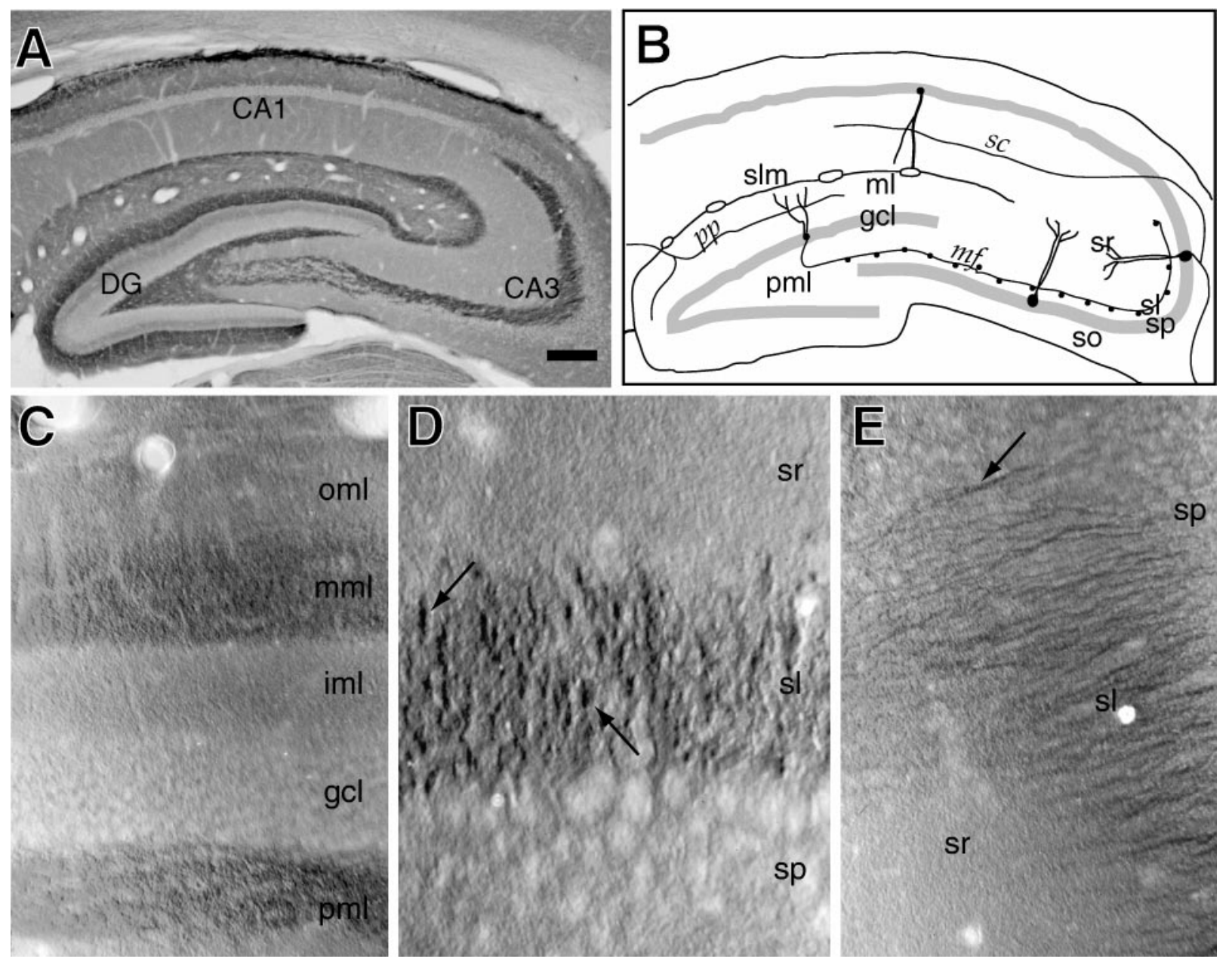

Figure 1. Kv1.4 is localized to the dentate gyrus middle molecular layer and to stratum lucidum. $A$, View of the dorsal hippocampus at low magnification after immunoperoxidase staining for Kv1.4. Reaction product is highest in the middle molecular layer, the polymorphic layer, and stratum lucidum. $B$, Drawing indicating the major tissue layers, the principal excitatory neurons, and their synapses. Pathways labeled are $p p$, the perforant (entorhinalhippocampal) path; $m f$, the mossy fiber tract; com, the commissural path; and $s c$, the Schaffer collateral path. Layers of the dentate gyrus are labeled $m l$, the molecular layer; $g c l$, the granule cell layer; and $\mathrm{pml}$, the polymorphic, or hilar, layer. Layers of the hippocampus are labeled $s o$, stratum oriens; $s p$, stratum pyramidale; $s r$, stratum radiatum; $s l m$, stratum lacunosum-moleculare; and $s l$ (in CA3 only), stratum lucidum. $C$, View of a portion of dentate gyrus at higher magnification. Layers are labeled as in B, but the molecular layer is divided into inner, middle, and outer regions ( $\mathrm{iml}, \mathrm{mml}$, and oml). Kv1.4 staining is present in several layers, and is highest in the $\mathrm{mml}$ and pml. Mml staining has a fine, homogeneous appearance. $D$, View of a portion of CA3 at higher magnification. Kv1.4 staining within sl has a patchy or punctate appearance (arrows) different from that seen in the mml. E, View of a portion of distal CA3 at higher magnification. In this region, Kv1.4 immunoreactivity (arrow) exhibits a fibrillar appearance different from that seen in $D$. Scale bars: $A, 0.25 \mathrm{~mm} ; C, E, 30 \mu \mathrm{m} ; D, 50 \mu \mathrm{m}$.

(Fig. 2A) and Kv1.4 (Fig. 2B) immunofluorescence seen in stratum lucidum, staining in the dentate occurred in small, evenly distributed puncta. This probably reflected the fact that perforant path axons pass through the molecular layer as individual axons or very small fasciculi and form small $(\sim 1 \mu \mathrm{m})$ termini (Laasch and Cowan, 1966; Matthews et al., 1976). Although in merged images from double-labeled confocal sections, the distribution of two markers appeared to overlap extensively (Fig. $2 F$ ), higher resolution imaging would be required to determine whether this represented colocalization within termini.

\section{Immunoelectron microscopy}

At the level of light microscopy, Kv1.4 distribution in the molecular layer of the dentate gyrus appeared different from that in stratum lucidum of CA3. In the middle molecular layer, Kv1.4 staining was rather homogeneous over the entire region that contained terminals; in stratum lucidum, it appeared fibrillar and patchy and seemed to arise from structures distinct from nerve terminals. To characterize the subcellular localization of the channel in these regions better, we examined sections reacted with Kv1.4 antibodies using the electron microscope.

\section{Dentate gyrus}

Thin sections of regions of the dentate gyrus cut from immunoreacted material exhibited the well described ultrastructural features of the region (Laasch and Cowan, 1966; Matthews et al., 1976). Within the middle molecular layer, the largest profiles within sections were the lightly contrasted, microtubule-filled distal portions of dendrites. Clustered in spaces between these dendrites were the smaller profiles of spines, myelinated and unmyelinated axons, and presynaptic boutons. Figure $3 A$ provides an orienting drawing indicating the region selected for analysis (compare with Fig. 1). Figure $3 B$ illustrates the typical spatial relationship between the granule cells, their dendrites, and perforant path derived afferents. Kv1.4 immunoreactivity appeared to be exclusively presynaptic, associated with axons and termini, but not with dendrites or 


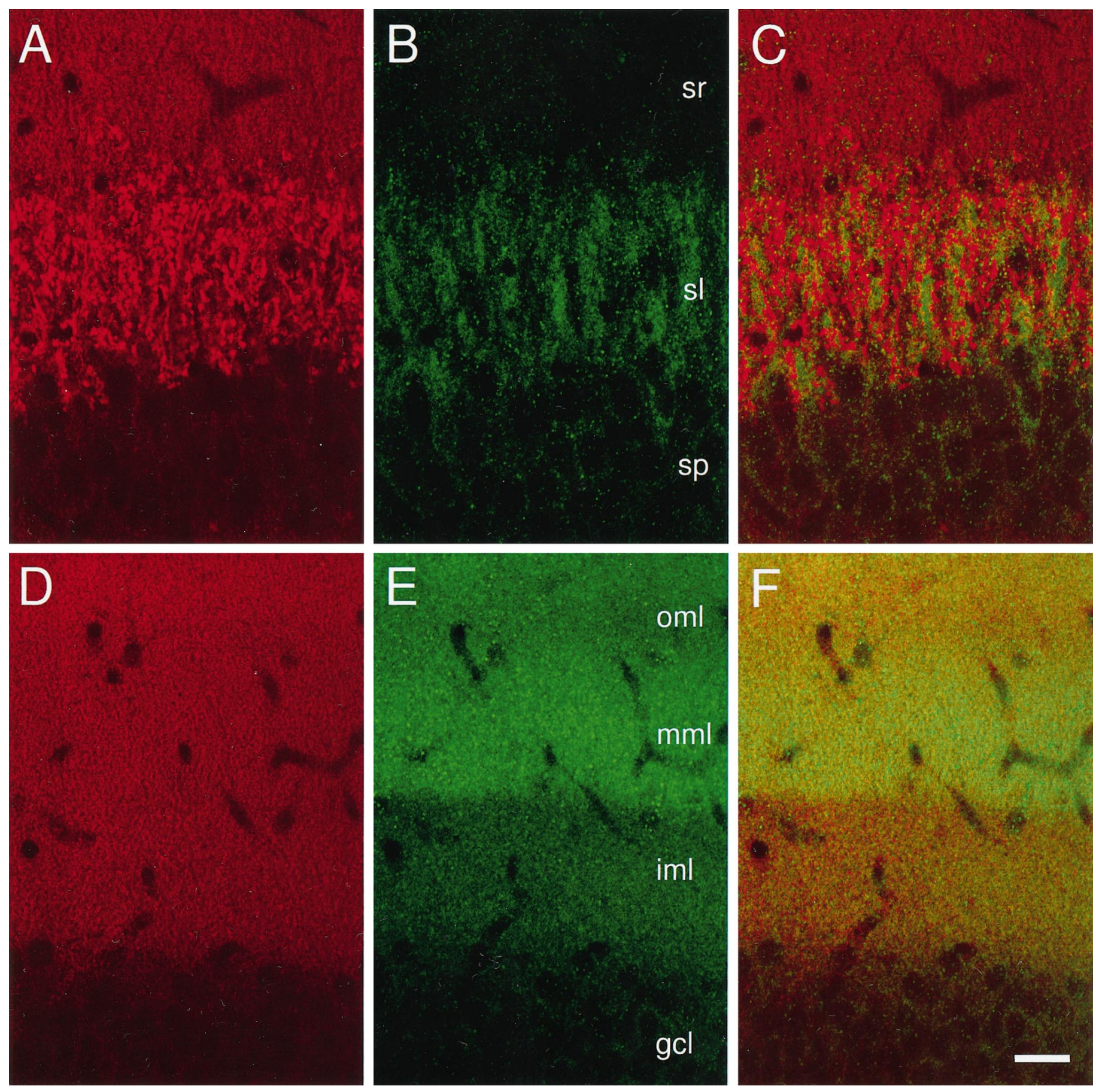

Figure 2. $A-F$, Localization of Kv1.4 and synaptophysin by confocal microscopy. $A$, Synaptophysin immunoreactivity in CA3. Immunofluorescence occurs at high density in patches within sl. Expression is lower in sr and sp. B, Kv1.4 immunoreactivity in CA3. Within sl, pattern appears similar to that observed for synaptophysin. $C$, Superimposition of $A$ and $B$. Kv1.4 and synaptophysin patches in sl are largely noncoinciding. $D$, Synaptophysin expression in the dentate. Immunoreactivity occurs in fine puncta throughout the molecular layer. Signal intensity is oml $>\mathrm{mml}$, iml $>$ gcl. $E$, Kv1.4 expression in the dentate. Signal intensity is $\mathrm{mml}>\mathrm{oml}>\mathrm{iml}>\mathrm{gcl}$. $F$, Superimposition of $D$ and $E$. Scale bar, $25 \mu \mathrm{m}$.

spines (Figs. 3, 4). Within transversely sectioned axons, Kv1.4 staining sometimes filled profiles homogeneously, but often was associated asymmetrically with a portion of the cell membrane (Fig. 3C,D). Axons sectioned lengthwise revealed a patchy, discontinuous distribution of Kv1.4 immunoreactivity, which sometimes adjoined vesicle-filled axonal dilations where en passante synapses were seen (Fig. 3D). Patches of reaction product also were noted within small myelinated fibers in the molecular and polymorphic layers (Fig. 3F). Kv1.4 immunoperoxidase staining was observed within synaptic boutons (Fig. 4). The dense stain was associated asymmetrically with a portion of the cell membrane. In many cases, the Kv1.4-immunopositive boutons appeared clearly as asymmetric, Gray's type 1 (excitatory) synapses onto spines (Fig. 4B-E). Immunopositive synapses exhibited the simple (Fig. $4 C-E$ ) or complex (Fig. 4B) morphologies described previously for the perforant path-derived synapses of this region (Laasch and Cowan, 

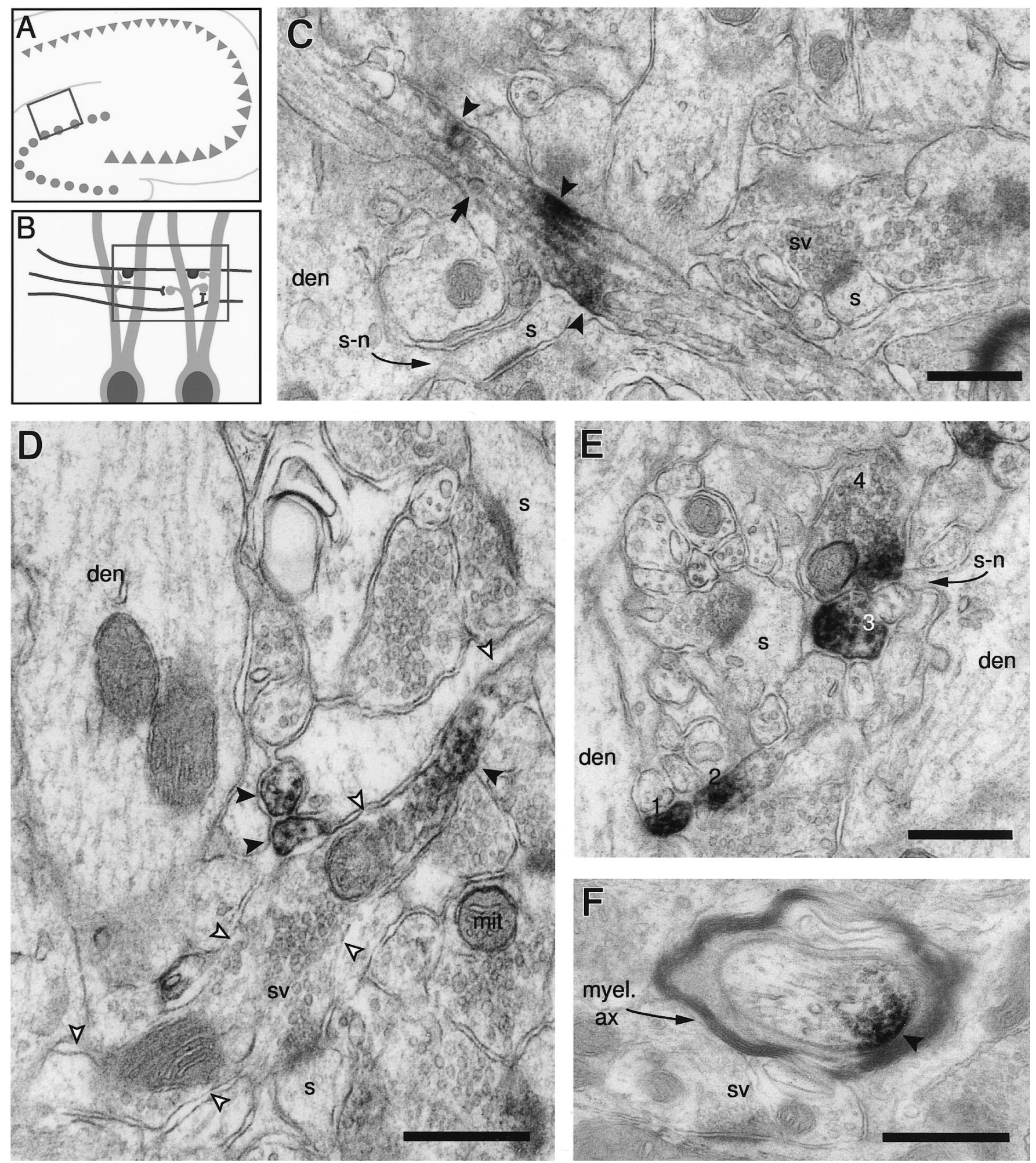

Figure 3. Immunoelectron microscopic localization of Kv1.4 on axons within the dentate gyrus. $A, B$, Schematic drawings indicating the area depicted in electron micrographs in $C-E$ and Figure 4. Box within $A$ contains a portion of the dentate molecular and granule cell layers and is expanded as $B$; box within $B$ encloses the middle molecular layer alone and includes representations of the main features contained within the accompanying electron micrographs: dendrites of granule cells that flank smaller profiles of perforant path-derived axons, their termini, and spines. $C$, Axon sectioned longitudinally exhibits membrane-associated puncta of immunoreaction product at three locations (arrowheads). Also notable within the stained axon are microtubules and a dense core granule (arrow). D, An axon (course indicated by white arrowheads) in longitudinal section synapses with an unlabeled spine. Label (dark arrowhead) is present in an axon near the synapse. Two small profiles in cross section are also labeled (dark arrowheads). E, Small labeled and unlabeled profiles in cross section crowded between two longitudinally sectioned dendrites. Labeled profiles (1-4) are of variable size, contain synaptic vesicles, and may represent portions of axons at various distances from termini. $F$, A small myelinated axon sectioned obliquely contains dense reaction product associated with the cell membrane (polymorphic layer). Den, Dendrite; mit, mitochondrion; $s$, spine; sv, synaptic vesicles. Scale bars, $0.5 \mu \mathrm{m}$. 

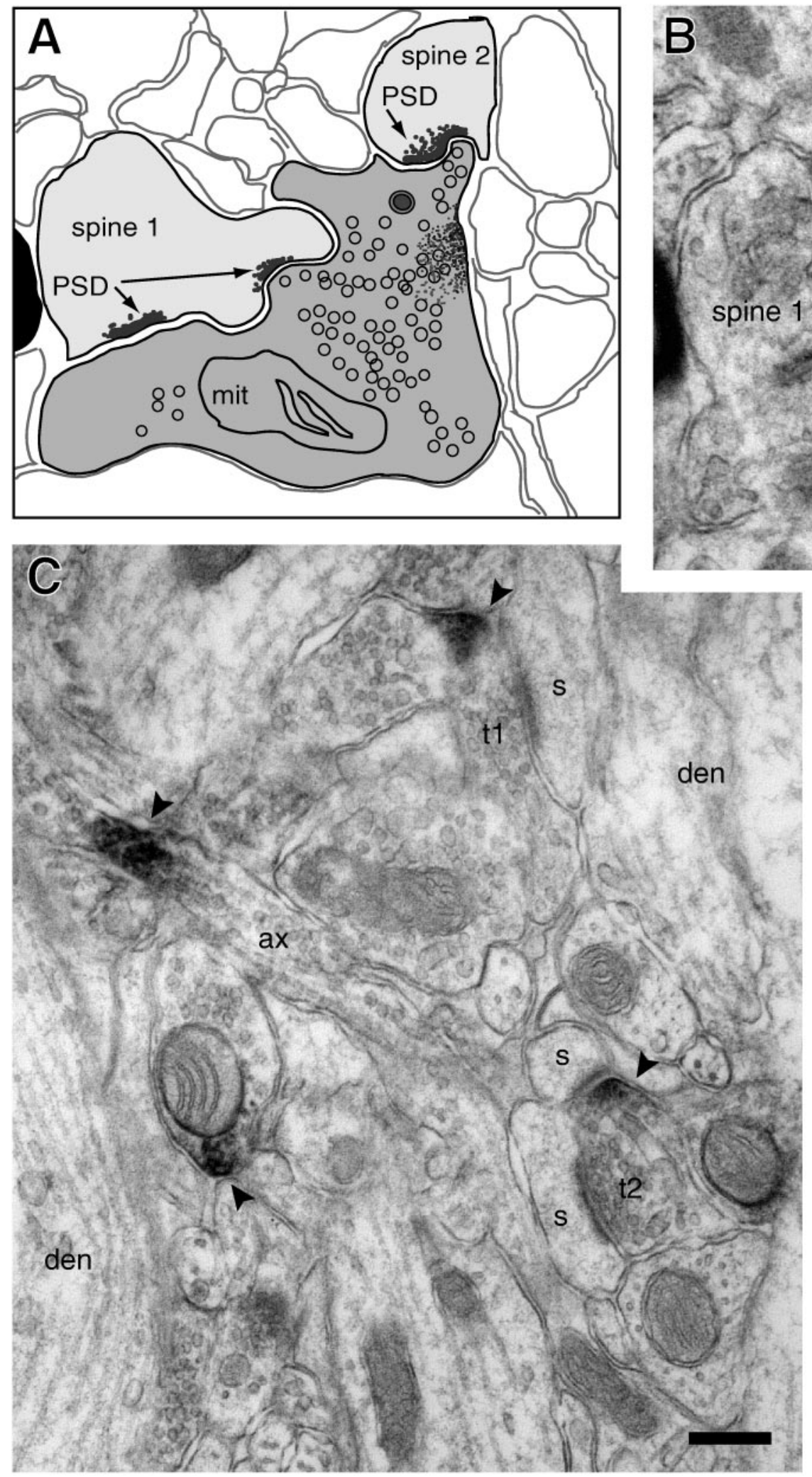
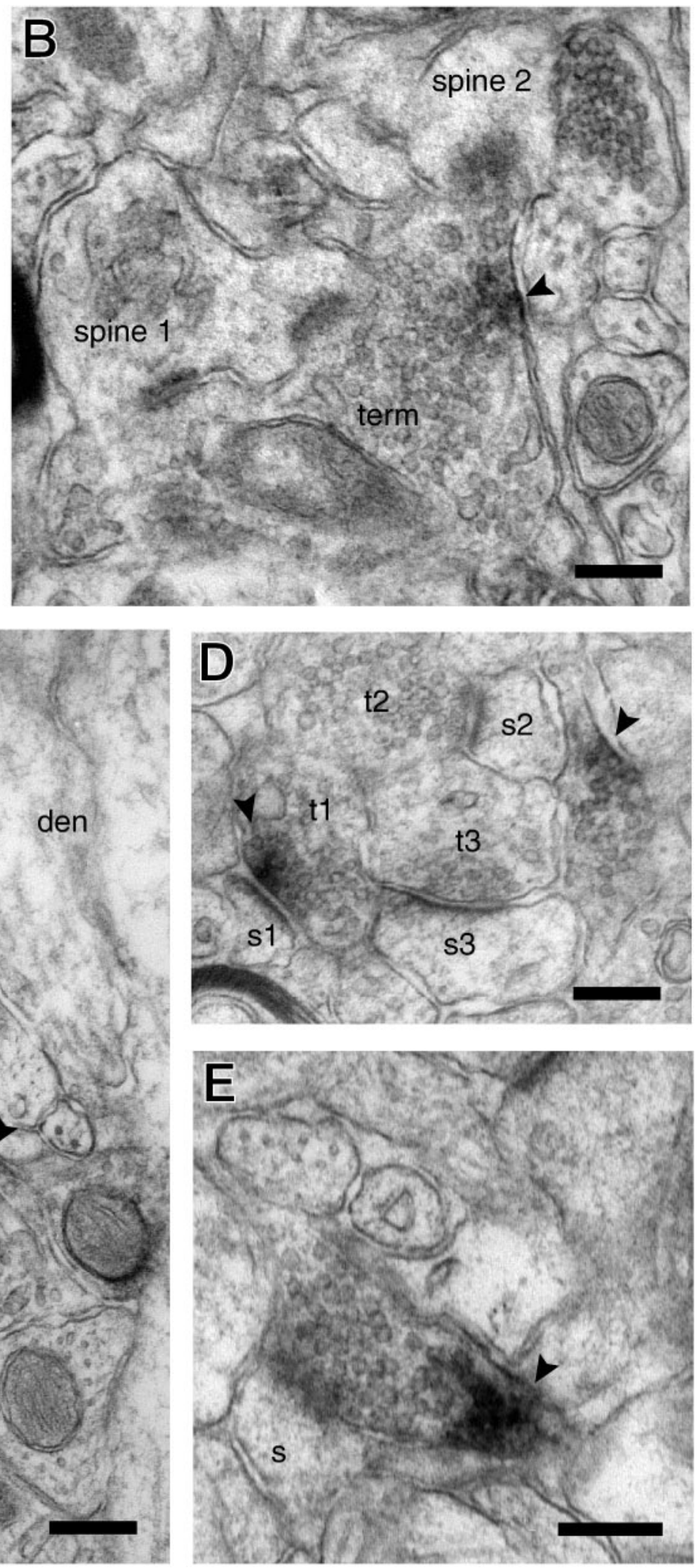

Figure 4. Kv1.4 localization within presynaptic termini in the middle molecular layer. $A$, Drawing based on the micrograph shown in $B$. $B$, Single, complex terminal forming three synapses with two spines. Immunoreaction product (arrowhead) appears to arise from portion of terminal membrane opposite from synaptic active zones. $C$, Membrane-associated stain is detected within two presynaptic termini. Within one (T1), reaction product is near, but apparently not within an active zone. The second labeled terminal (T2) synapses with two spines. Reaction product (arrowheads) also is noted within an axon $(a x)$ seen in longitudinal section and associated with the membrane of another profile that contains clear synaptic vesicles and dense core granules. $D$, Cluster of three synapses. In one terminal (T1), reaction product appears to arise from the membrane at the active zone. $E$, Stain in a small profile of a presynaptic terminal. Scale bars, $0.2 \mu \mathrm{m}$. Abbreviations are as in Figure 3. 
1966; Matthews et al., 1976). The immunoperoxidase stain occasionally appeared to arise near the presynaptic active zone (Fig. $4 D$ ). More typically, it arose from the axonal neck or a portion of the nerve terminal membrane within the synaptic bouton distant from the active zone (Figs. 3D, 4B, C, E).

\section{CA3}

Within stratum pyramidale of CA3, Kv1.4 immunoreactivity was associated with the cytoplasmic aspects of the endoplasmic reticulum of pyramidal cells but not the cell membrane. Stratum lucidum contained three principal structures: pyramidal cell dendrites, tightly packed fasciculi of mossy fiber axons, and synaptic complexes (Fig. 5B). The mossy fiber-CA3 synaptic structures, as described previously (Blackstad and Kjaerheim, 1961; Laasch and Cowan, 1966; Claiborne et al., 1986; Chicurel and Harris, 1992), consisted of unusual presynaptic expansions-complex, multilobulated profiles, filled with synaptic vesicles, in association with the so-called "thorny excrescences"- the complex spines and spine branches of the CA3 pyramidal cells. Tightly fasciculated groupings of mossy fiber axons frequently were located near these synapses. Although the individual axons were small (diameters of $0.2-0.5$ $\mu \mathrm{m}$ ), fasciculi typically contained $\sim 100-200$ axons, giving an overall size similar to that of an individual presynaptic expansion.

Kv1.4 immunoreactivity was observed most frequently within the fasciculated mossy fiber axons (Fig. 5C,D). Axons sectioned transversely sometimes appeared to be filled homogeneously with immunoperoxidase stain, but in many cases, dense stain appeared to be associated asymmetrically with the cytoplasmic side of a portion of the axonal membrane (Fig. 5D, inset). Axonal profiles captured in a more lengthwise orientation sometimes appeared to be filled for $>1 \mu \mathrm{m}$ with reaction product, but more often there were smaller patches $(<1 \mu \mathrm{m})$ of staining that either filled the axon (Fig. $5 F$ ) or were associated asymmetrically with the membrane on one side. Prominent Kv1.4 immunoreactivity also was noted at portions of axons immediately adjacent to expansions (Fig. 5D,E; see Discussion).

Kv1.4 immunoreactivity was rarely observed associated with the membranes of the mossy fiber expansions. When such staining was noted, it appeared to be present at a narrow point within the expansion lying between two or more larger, vesicle-filled areas. However, Kv1.4 immunoreactivity was not observed at or immediately adjacent to presynaptic release sites and was absent from dendritic branches and spines of the CA3 pyramidal cells.

\section{DISCUSSION}

The neuronal cell membrane may be viewed as consisting of several distinct functional domains. The contribution made by an ion channel protein to the cell depends both on the intrinsic properties of the channel and on the particular subcellular location where it is inserted into the cell membrane (Llinas, 1988). A growing body of evidence suggests that the electrical properties of each neuronal type are regulated through precise control of the membrane localization of channels and receptors at specific sites within subcellular domains (Baude et al., 1993; Wang et al., 1993; Laube et al., 1996; McNamara et al., 1996; Alonso et al., 1997). We have found that Kv1.4 is expressed within the hippocampal formation on axons and within or near the presynaptic termini of two types of excitatory neurons. Within the dentate gyrus molecular layer, Kv1.4 immunoreactivity is detected within both the preterminal, unmyelinated portions of the perforant pathway axons and their presynaptic boutons. In CA3, Kv1.4 immunoreactivity is prominent in the densely packed fasciculi of the mossy fiber axons and can be observed adjacent to the mossy fiber terminal expansions. However, we did not detect Kv1.4 staining associated with the membranes of the large expansions where transmitter release sites are found.

\section{Kv1.4 is localized in the hippocampus on unmyelinated axons of glutamatergic neurons}

We found evidence for Kv1.4 expression by glutamatergic neurons forming axodendritic synapses in the hippocampus but not for expression by inhibitory neurons forming axosomatic synapses. Although staining was seen associated with myelinated fibers (e.g., Fig. $3 F$ ), the most abundant staining was associated with unmyelinated fibers. Previous studies using degeneration methods suggest that at least $70 \%$ of the excitatory synapses found within the outer two-thirds of the dentate molecular layer represent perforant path input onto granule cell dendrites (Matthews et al., 1976). Furthermore, these synapses exhibit characteristic morphology that is identified readily in thin sections (Laasch and Cowan, 1966). For these reasons, it is highly likely that the stained profiles we observed in the molecular layer represent, at least in large part, perforant path-derived axons and termini. The identification of the stained axons seen in CA3 as mossy fibers is unambiguous because of the characteristic appearance of the mossy fiber fasciculi and synaptic expansions.

The function and distribution of voltage-gated ion channels along vertebrate axonal membranes have been studied most extensively in the case of peripheral myelinated axons (Hille, 1992; Ritchie, 1995). On these axons, the nodes of Ranvier possess sodium channels at high density but few voltage-gated potassium channels. The rapid repolarization of the action potential appears to result from a high resting conductance. Voltage-gated potassium channels are present at greatest density at and near paranodal regions (Chiu and Schwartz, 1987; Wang et al., 1993; Mi et al., 1995), where they may provide a more specialized function facilitating the propagation of the action potential from node to node. Much less has been learned about the function and distribution of voltage-gated channels on central unmyelinated axons (Waxman, 1995). Freeze-fracture images of these axons exhibit at far lower density the intramembranous particles thought to represent channels and other membrane proteins (Black et al., 1981). We have found patches of Kv1.4 immunoreactivity along the unmyelinated axons in both perforant path and mossy fiber tracts, suggesting that rapidly inactivating voltage-gated potassium channels (A-type) are present on these unmyelinated axons of central neurons.

A-type channels expressed on the somatodendritic portions of neuronal membranes play key roles in the process that transforms graded excitatory and inhibitory influences into a coded pattern of action potential firing (Connor and Stevens, 1971; Neher, 1971; Hoffman et al., 1997). Most axonal preparations used in physiologic studies lack A-type channels; these axons propagate action potentials presented to them, but are unable to respond in graded fashion to stimuli of different intensities (Guttmann and Barnhill, 1970; Hille, 1992). By contrast, the lightly myelinated axons of crustacean motor neurons possess A-currents that underlie their ability to fire at different frequencies in response to stimuli of different intensities (Hodgkin, 1948; Connor, 1975). Recent experiments using hippocampal slices indicate that axonal A-type channels may regulate the efficiency with which somatically recorded action potentials reach distal axonal branches and evoke neurotransmitter release (Debanne et al., 1997). Our anatomical studies provide additional evidence that, for some mammalian central neurons, axonal functions may not be limited to faithful action potential propagation. 

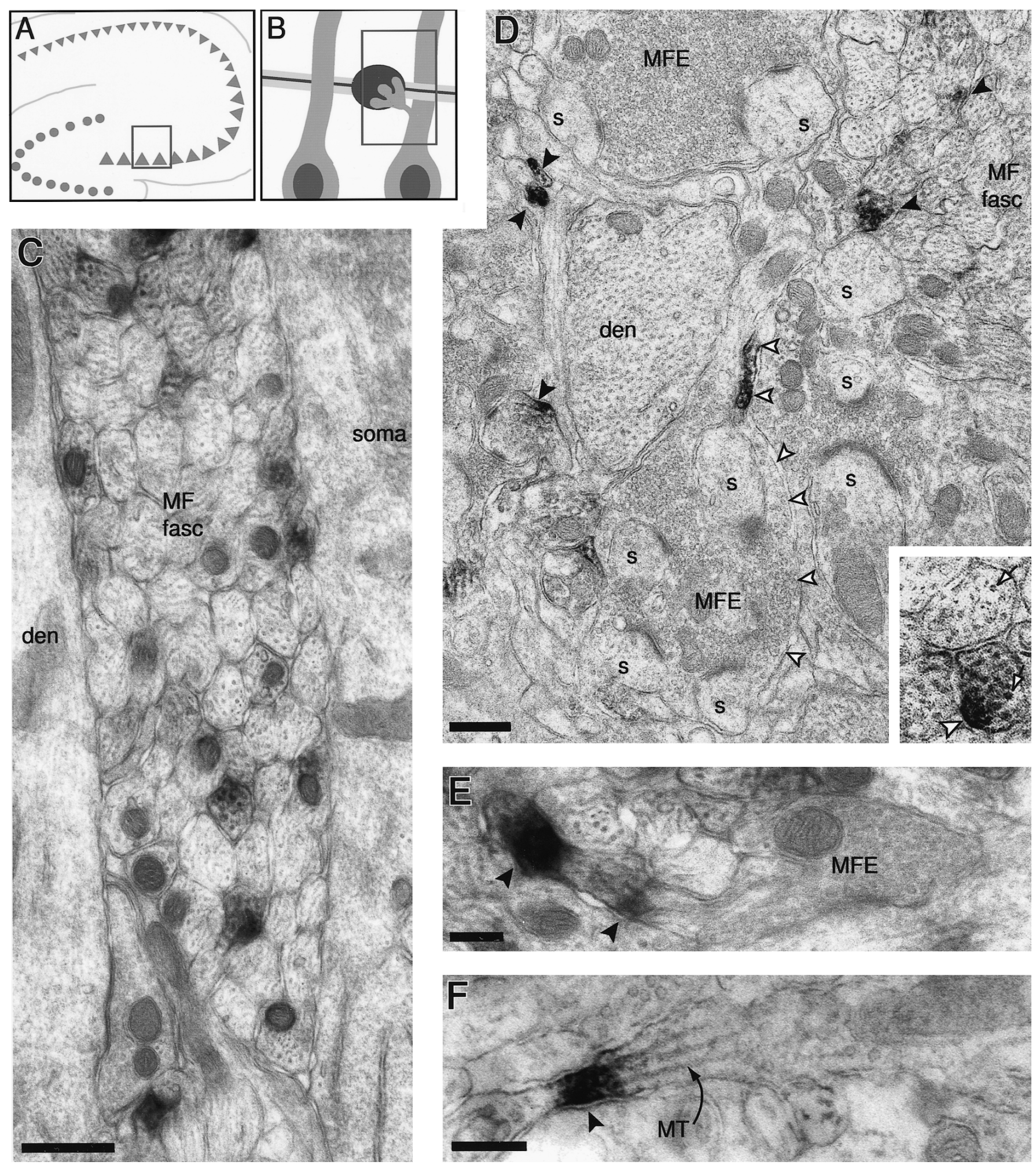

Figure 5. Kv1.4 localization in the stratum lucidum of CA3. $A, B$, Schematic drawings indicating the area depicted in electron micrographs. Box within $A$ encloses a portion of stratum pyramidale and stratum lucidum and is expanded as $B$; box within $B$ encloses representations of main features of the accompanying electron micrographs: large proximal dendrites of pyramidal cells are flanked either by fasciculi of mossy fiber axons or by synaptic structures formed by mossy fiber expansions and complex pyramidal cell spines. $C$, Labeled axons within a mossy fiber fasciculus (MF fasc) pass between a CA3 pyramidal cell soma (soma) and the proximal dendrite (den) of another pyramidal cell. $D$, Lower magnification view of stratum lucidum containing a mossy fiber fasciculus with transverse and obliquely sectioned mossy fibers, a pyramidal cell dendritic branch (den), and a "synaptic complex" consisting of multiple spine branches $(s)$ derived from a pyramidal cell "thorny excrescence" and synaptic vesicle-filled, multilobulated mossy fiber expansions $(M F E)$. Numerous stained axons in cross section are noted (solid arrowheads). Another axon, sectioned lengthwise, is stained heavily near its transition into a mossy fiber expansion (open arrowheads). E, A longitudinally sectioned axon within a mossy fiber fasciculus contains immunoreaction product near the site of origin of a presynaptic expansion. $F$, Stained small axon sectioned longitudinally. $M T$, Microtubule. Scale bars: $C, D, 0.5 \mu \mathrm{m} ;(0.25 \mu \mathrm{m}$ in $D$, inset); $E, 0.2 \mu \mathrm{m} ; F, 0.2 \mu \mathrm{m}$. 
Axons may contribute dynamically, along with somatodendritic domains, to the determination of firing frequency.

\section{Kv1.4 is localized at nerve termini in the dentate molecular layer and near mossy fiber termini within CA3}

Within the outer two-thirds of the dentate molecular layer, perforant path axons form small $(\sim 1 \mu \mathrm{m})$ termini that synapse on small spines derived from the distal dendrites of the granule cells. The small size of these Kv1.4-immunopositive termini make direct study of their electrophysiologic properties difficult. Studies using unusually large termini in invertebrates and vertebrates have shown that calcium entry and, therefore, the amount of neurotransmitter release are sensitive functions of action potential duration. Presynaptic voltage-gated potassium channels in these preparations play key roles in the determination of action potential duration (Augustine, 1990; Jackson, 1991; Byrne and Kandel, 1996). The presence of Kv1.4 immunoreactivity within termini in the middle molecular layer suggests that Kv1.4 may contribute to the electrical properties of these termini and, therefore, the process of neurotransmitter release.

The mossy fiber-CA3 pyramidal cell synapses exhibit very different morphology from those found in the middle molecular layer. Although each mossy fiber axon traverses the entire length of CA3, it forms synaptic contacts with only a small number of CA3 pyramidal cells. These synapses are clustered at large, multilobulated expansions that occur at regularly spaced intervals $(\sim 100 \mu \mathrm{m})$ along the length of each mossy fiber axon. We found Kv1.4 immunoreactivity associated with mossy fiber axons, including "neck" portions of axons adjacent to synapse-bearing expansions. The mossy fiber expansions themselves, however, did not exhibit Kv1.4 immunoreactivity. Thus, Kv1.4 may help shape the propagated mossy fiber action potential and may regulate the efficiency with which the action potential may invade particular presynaptic expansions. Recent experiments involving the metabotropic glutamate receptor mGluR2, which also appears to be targeted to the axonal necks near mossy fiber termini, suggest that this localization is sufficiently close to release sites to strongly influence neurotransmission (Yokoi, 1996).

\section{Structural and functional implications}

Our ability to draw conclusions regarding the functional role played by the Kv1.4-containing channels localized by our studies is limited by the present uncertainty regarding the complete subunit composition of the channels. Channels formed by coexpression of Kv1.4 with other Shaker family subunits exhibit voltage-dependent and kinetic properties that are qualitatively similar to, although quantitatively different from, those formed by Kv1.4 subunits alone (Po et al., 1993; Rettig et al., 1994; Heinemann et al., 1996). In rat brain, it has been shown that some Kv1.4 subunits form heteromeric channels with Kv1.2 (Sheng et al., 1993) and Kv $\beta 1 / 2$ (Rhodes et al., 1995). Within the dentate gyrus, Kv1.2 immunoreactivity has been observed within the middle molecular layer by light microscopy and within axons and excitatory presynaptic termini by electron microscopy (Sheng et al., 1994; Wang et al., 1994). Kv1.1, Kv1.2, Kv1.3, Kv1.6, and Kv $\beta 1 / 2$ immunoreactivity have been detected within stratum lucidum by light microscopy (Sheng et al., 1993; Rhodes et al., 1995; Veh et al., 1995). Double-immunolabeling studies using electron microscopy may clarify whether the Kv1 family channels expressed on the entorhinal-hippocampal axons and termini and mossy fiber axons are likely to include heteromers of these subunits. Interestingly, SAP-97, a member of the family of membrane-associated guanylate kinase scaffold proteins, has been shown by immunoelectron microscopy to be expressed in dentate molecular layer excitatory termini and mossy fiber axons; staining of mossy fiber expansions was not reported (Muller et al., 1995). It would be of interest to determine whether Kv1.4 and SAP-97 are associated in these locations and, if so, what other, if any, proteins are held near Kv1.4 via interaction with SAP-97s SH3, PDZ, and GK domains.

When expressed in heterologous systems, Kv1.4 is inhibited by phorbol esters and by transmitter receptors linked to activation of protein kinase C (Okada et al., 1992; Murray et al., 1994). Metabotropic neurotransmitter receptors linked to protein kinase $\mathrm{C}$ are richly expressed in the hippocampal formation (Amaral and Witter, 1995), but their cell type and subcellular localizations are only beginning to be described in detail (Baude et al., 1993; Shigemoto et al., 1993; Levey et al., 1995). Whether this form of regulation of Kv1.4 activity occurs in the hippocampus may be clarified by additional studies.

A second noteworthy feature of heterologously expressed Kv1.4 is its fast inactivation and long-lasting desensitization. The kinetics and molecular mechanisms underlying these features have been studied in detail (Ruppersberg et al., 1991; Baukrowitz and Yellen, 1995; Liu et al., 1996; Roeper et al., 1997). These properties make Kv1.4 an obligate integrator of brief depolarizations, such as those associated with propagated action potentials, over periods as long as tens of seconds. It would be predicted that the action potentials propagated along axons bearing Kv1.4 channels would broaden when firing frequencies increased sufficiently to induce Kv1.4 inactivation and/or desensitization.

The rapid onset and delayed recovery of Kv1.4 inactivation is of particular interest in view of the prominent frequency-dependent plasticity of the mossy fiber synapses and the proposed contribution of these synapses to hippocampal network function. Mossy fiber synapses studied in slice preparations exhibit robust enhancement of synaptic transmission during repetitive stimulation, called frequency facilitation (Regehr et al., 1994; Salin et al., 1996). Like the inactivation of Kv1.4, mossy fiber frequency facilitation occurs at low stimulus frequencies between 0.025 and $0.33 \mathrm{~Hz}$.

In models of hippocampal function, mossy fiber input plays a key role, introducing fragments of sensory experience into the autoassociative CA3-CA1 network, where they are processed into stable, multimodal memories (Rolls, 1990). It will be interesting to determine in future experiments whether Kv1.4 is involved in mossy fiber short-term frequency-dependent plasticity and thereby, perhaps, contributes to the discrimination between those stimuli associated with experience of sufficient importance for storage in memory and those that are not.

\section{REFERENCES}

Alonso G, Widmer H (1997) Clustering of KV4.2 potassium channels in postsynaptic membrane of rat supraoptic neurons: an ultrastructural study. Neuroscience 77:617-621.

Amaral DG, Witter MP (1995) Hippocampal formation. In: The rat nervous system (Paxinos G, ed), pp 433-495. San Diego: Academic.

Augustine GJ (1990) Regulation of transmitter release at the squid giant synapse by presynaptic delayed rectifier potassium current. J Physiol (Lond) 431:343-364.

Baude A, Nusser Z, Roberts JD, Mulvihill E, McIlhinney RA, Somogyi P (1993) The metabotropic glutamate receptor (mGluR1 alpha) is concentrated at perisynaptic membrane of neuronal subpopulations as detected by immunogold reaction. Neuron 11:771-787.

Baukrowitz T, Yellen G (1995) Modulation of $\mathrm{K}^{+}$current by frequency and external $\left[\mathrm{K}^{+}\right]$: a tale of two inactivation mechanisms. Neuron 15:951-960.

Black JA, Foster RE, Waxman SG (1981) Freeze-fracture ultrastructure of rat CNS and PNS nonmyelinated axolemma. J Neurocytol 10:981-993. 
Blackstad TW, Kjaerheim A (1961) Special axo-dendritic synapses in the hippocampal cortex. Electron and light microscopic studies on the layer of mossy fibers. J Comp Neurol 117:133-159.

Brown TH, Zador AM (1990) Hippocampus. In: The synaptic organization of the brain (Shepherd GM, ed), pp 346-387. New York: Oxford UP.

Byrne JH, Kandel ER (1996) Presynaptic facilitation revisited: state and time dependence. J Neurosci 16:425-435.

Chandy KG, Gutman GA (1995) Voltage-gated potassium channel genes. In: Handbook of receptors and channels: ligand and voltagegated channels (North RA, ed), pp 1-71. Boca Raton, FL: CRC.

Chicurel ME, Harris KM (1992) Three-dimensional analysis of the structure and composition of CA3 branched dendritic spines and their synaptic relationships with mossy fiber boutons in the rat hippocampus. J Comp Neurol 325:169-182.

Chiu SY, Schwartz W (1987) Sodium and potassium currents in acutely demyelinated internodes of rabbit sciatic nerves. J Physiol (Lond) 292:631.

Claiborne BJ, Amaral DG, Cowan WM (1986) A light and electron microscopic analysis of the mossy fibers of the rat dentate gyrus. J Comp Neurol 246:435-458

Connor JA (1975) Neural repetitive firing: a comparative study of membrane properties of crustacean walking leg axons. J Neurophysiol 38:922-931.

Connor JA, Stevens CF (1971) Voltage clamp studies of a transient outward membrane current in gastropod neuronal somata. J Physiol (Lond) 213:21-30.

Dailey ME, Buchanan J, Bergles DE, Smith SJ (1994) Mossy fiber growth and synaptogenesis in rat hippocampal slices in vitro. J Neurosci 14:1060-1078.

Debanne D, Guerineau NC, Gahwiler BH, Thompson SM (1997) Action-potential gated by an axonal $\mathrm{I}(\mathrm{A})$-like $\mathrm{K}^{+}$conductance in hippocampus. Nature 389:286-289.

Grabs D, Bergmann M, Schuster T, Fox PA, Brich M, Gratz M (1994) Differential expression of synaptophysin and synaptoporin during preand postnatal development of the rat hippocampal network. Eur J Neurosci 6:1765-1771.

Guttmann R, Barnhill R (1970) Oscillations and repetitive firing in squid axons. Comparison of experiments with computations. J Gen Physiol 55:104-118.

Heinemann SH, Rettig J, Graack HR, Pongs O (1996) Functional characterization of $\mathrm{Kv}$ channel beta-subunits from rat brain. J Physiol (Lond) 493:625-633.

Hille B (1992) Ionic channels of excitable membranes. Sunderland, MA: Sinauer.

Hodgkin AL (1948) The local electric changes associated with repetitive action in a non-medullated axon. J Physiol (Lond) 107:165-181.

Hoffman DA, Magee JC, Colbert CM, Johnston D (1997) $\mathrm{K}^{+}$channel regulation of signal propagation in dendrites of hippocampal pyramidal neurons. Nature 387:869-875.

Jackson MB, Konnerth A, Augustine GJ (1991) Action potential broadening and frequency-dependent facilitation of calcium signals in pituitary nerve terminals. Proc Natl Acad Sci USA 88:380-384.

Jan LY, Jan YN (1997) Cloned potassium channels from eukaryotes and prokaryotes. Annu Rev Neurosci 20:91-123.

Laasch RH, Cowan WM (1966) Electron microscopic studies of the dentate gyrus of the rat. J Comp Neurol 128:359-396.

Laube G, Roper J, Pitt JC, Sewing S, Kistner U, Garner CC, Pongs O, Veh RW (1996) Ultrastructural localization of Shaker-related potassium channel subunits and synapse-associated protein 90 to septate-like junctions in rat cerebellar pinceaux. Brain Res Mol Brain Res 42:51-61.

Levey AI, Edmunds SM, Koliatsos V, Wiley R, Heilman CJ (1995) Expression of $\mathrm{m} 1-\mathrm{m} 4$ muscarinic acetylcholine receptor proteins in rat hippocampus and regulation by cholinergic innervation. J Neurosci 15:4077-4092.

Liu Y, Jurman ME, Yellen G (1996) Dynamic rearrangement of the outer mouth of a $\mathrm{K}^{+}$channel during gating. Neuron 16:859-867.

Llinas RR (1988) The intrinsic electrophysiological properties of mammalian neurons: insights into central nervous system function. Science 242:1654-1664.

Matthews DA, Cotman C, Lynch G (1976) An electron microscopic study of lesion-induced synaptogenesis in the dentate gyrus of the adult rat. I. Magnitude and time course of degeneration. Brain Res 115:1-21.

McNamara NM, Averill S, Wilkin GP, Dolly JO, Priestley JV (1996) Ultrastructural localization of a voltage-gated $\mathrm{K}^{+}$channel alpha subunit (KV 1.2) in the rat cerebellum. Eur J Neurosci 8:688-699.
Mi H, Deerinck TJ, Ellisman MH, Schwarz TL (1995) Differential distribution of closely related potassium channels in rat Schwann cells. J Neurosci 15:3761-3774.

Muller BM, Kistner U, Veh RW, Cases-Langhoff C, Becker B, Gundelfinger ED, Garner CC (1995) Molecular characterization and spatial distribution of SAP97, a novel presynaptic protein homologous to SAP90 and the Drosophila discs-large tumor suppressor protein. J Neurosci 15:2354-2366.

Murray KT, Fahrig SA, Deal KK, Po SS, Hu NN, Snyders DJ, Tamkun MM, Bennett PB (1994) Modulation of an inactivating human cardiac $\mathrm{K}^{+}$channel by protein kinase C. Circ Res 75:999-1005

Neher E (1971) Two fast transient current components during voltage clamp on snail neurons. J Gen Physiol 58:36-53.

Nicoll RA, Malenka RC (1995) Contrasting properties of two forms of long-term potentiation in the hippocampus. Nature 377:115-118.

Okada H, Ishii K, Nunoki K, Abe T, Taira N (1992) Modulation of transient type $\mathrm{K}$ channel cloned from rat heart. Biochem Biophys Res Commun 189:430-436.

Pardo LA, Heinemann S, Terlau H, Ludwig U, Lorra C, Pongs O, Stuhmer W (1992) Extracellular $\mathrm{K}^{+}$specifically modulates a rat brain $\mathrm{K}^{+}$channel. Proc Natl Acad Sci USA 89:2466-2470.

Po S, Roberds S, Snyders D, Tamkun MM, Bennett PB (1993) Heteromultimeric assembly of human potassium channels. Molecular basis of a transient outward current? Circ Res 72:1326-1336.

Regehr WG, Delaney KR, Tank DW (1994) The role of presynaptic calcium in short-term enhancement at the hippocampal mossy fiber synapse. J Neurosci 14:523-537.

Rettig J, Heinemann SH, Wunder F, Lorra C, Parcej DN, Dolly JO, Pongs O (1994) Inactivation properties of voltage-gated $\mathrm{K}^{+}$channels altered by presence of beta-subunit. Nature 369:289-294.

Rhodes KJ, Keilbaugh SA, Barrezueta NX, Lopez KL, Trimmer JS (1995) Association and colocalization of $\mathrm{K}^{+}$channel alpha- and betasubunit polypeptides in rat brain. J Neurosci 15:5360-5371.

Ritchie JM (1995) Physiology of axons. In: The axon (Waxman SG, Kocsis JD, Stys PS, eds), pp 68-96. New York: Oxford UP.

Roeper J, Lorra C, Pongs O (1997) Frequency-dependent inactivation of mammalian A-type $\mathrm{K}^{+}$channel KV1.4 regulated by $\mathrm{Ca}_{2}{ }^{+} /$calmodulindependent protein kinase. J Neurosci 17:3379-3391.

Rolls ET (1990) Theoretical and neurophysiological analysis of the functions of the primate hippocampus in memory. Cold Spring Harb Symp Quant Biol 55:995-1006.

Rudy B (1988) Diversity and ubiquity of K channels. Neuroscience 25: $729-749$.

Ruppersberg JP, Frank R, Pongs O, Stocker M (1991) Cloned neuronal IK(A) channels reopen during recovery from inactivation. Nature 353:657-660.

Salin PA, Scanziani M, Nicoll RA, Malenka RC (1996) Distinct shortterm plasticity at two excitatory synapses in the hippocampus. Proc Natl Acad Sci USA 93:13304-13309.

Sheng M, Tsaur ML, Jan YN, Jan LY (1992) Subcellular segregation of two A-type potassium channels in rat central neurons. Neuron 9:271-284.

Sheng M, Liao YJ, Jan YN, Jan LY (1993) Presynaptic A-current based on heteromultimeric $\mathrm{K}^{+}$channels detected in vivo. Nature 365:72-75.

Shigemoto R, Nomura S, Ohishi H, Sugihara H, Nakanishi S, Mizuno N (1993) Immunohistochemical localization of a metabotropic glutamate receptor, mGluR5, in the rat brain. Neurosci Lett 163:53-57.

Stuhmer W, Ruppersberg P, Schroter KH, Sakmann B, Stocker M, Giese KP, Perschke A, Baumann A, Pongs O (1989) Molecular basis of functional diversity of voltage-gated potassium channels. EMBO J 8:3235-3244.

Veh RW, Lichtinghagen R, Sewing S, Wunder F, Grumbach IM, Pongs O (1995) Immunohistochemical localization of five members of the Kv1 channel subunits: contrasting subcellular locations and neuron-specific co-localizations in rat brain. Eur J Neurosci 7:2189-2205.

Wang H, Kunkel DD, Martin TM, Schwartzkroin PA, Tempel BL (1993) Heteromultimeric $\mathrm{K}^{+}$channels in terminal and juxtaparanodal regions of neurons. Nature 365:75-79.

Waxman SG (1995) Voltage-gated ion channels in axons: localization, function, and development. In: The axon (Waxman SG, Kocsis JD, Stys PS, eds), pp 218-244. New York: Oxford UP.

Yokoi M, Kobayashi K, Manabe T, Takahashi T, Sakaguchi I, Katsuura G, Shigemoto R, Ohishi H, Nomura S, Nakamura K, Nakao K, Katsuki, M, Nakanishi S (1996) Impairment of hippocampal mossy fiber LTD in mice lacking mGluR2. Science 273:645-647. 